\title{
Congenital Pelvi-ureteric Junction Obstruction Associated with Crossing Lower Pole Vessels
}

\author{
Abubakar Sadiq Muhammad ${ }^{1,2 *}$ \\ ${ }^{1}$ Department of Surgery, IMAN Hospital Runjin Sambo, Sokoto \\ ${ }^{2}$ Usmanu Danfodiyo University Teaching Hospital Sokoto, Nigeria
}

*Corresponding author: Abubakar Sadiq Muhammad, Usmanu Danfodiyo

University Teaching Hospital Sokoto, Nigeria.

Received Date: January 29, 2021

Published Date: February 23, 2021

\begin{abstract}
Background: Congenital pelvi-ureteric junction obstruction [PUJO] occurs when there is impairment of flow of urine from the renal pelvis to the proximal ureter due to inherited abnormalities of pelvi-ureteric junction [PUJ]. The presentation is usually at the $4^{\text {th }}$ or $5^{\text {th }}$ decade of life. It may rarely be associated with crossing lower pole vessel [CLPV]. Treatment is by Anderson- Hynes [dismembered] pyeloplasty which remove the abnormal PU] and transposes the PUJ anterior to the offending vessels. I report a case of 45-year-old man with congenital PUJO associated with crossing lower pole vessel vessels who had dismembered Anderson -Hynes pyeloplasty.

Case report: This is a 45-year-old man who presented with 4 years history of recurrent colicky left flank pain which was relieved by passing large volume of urine. The general examination was non remarkable. The left kidney was ballotable. The abdominopelvic computerized urogram revealed severe left hydronephrosis and hyperdense structure in the region of the left kidney. He had exploration via left Gibson incision with finding of multiple crossing lower pole vessels and aperistaltic segment at PUJ. He had excision of the abnormal PUJ, transposition of the crossing vessels posteriorly and dismembered Anderson-Hynes pyeloplasty. He had uneventful recovery and was discharged home 5 days postoperatively.

Conclusion: Congenital PUJO associated with lower pole vessel is rare and may present in the $5^{\text {th }}$ decade of life. Anderson- Hynes dismembered pyeloplasty is the procedure of choice and associated with good outcome.
\end{abstract}

Keywords: Congenital; Pelvi-ureteric junction obstruction; Crossing vessels; Dismembered pyeloplasty; Anderson hynes; Hydronephrosis

Abbreviations: PUJO: Pelvi-ureteric junction obstruction; PUJ: Pelvi-ureteric junction; CLPV: Crossing lower pole vessel

\section{Introduction}

Congenital pelvi-ureteric junction obstruction [PUJO] occurs when flow of urine is impeded from renal pelvis to the proximal ureter due to inherited abnormalities at pelvi-ureteric junction [PUJ] [1]. It may also be acquired from stone disease, inflammatory/ infective conditions and urothelial carcinoma of the renal pelvis [2]. The inherited causes may be intrinsic or extrinsic [2]. The intrinsic causes include aperistaltic segment due abnormal musculature, valves and folds. The extrinsic causes include crossing lower pole vessel, adhesions and bands [2]. The crossing lower pole vessel is the cause of obstruction in $11-20 \%$ of cases [3]. This is referred to currently to as vascular bar [4]. It may also co-exist with other causes. Even though a congenital problem, the presentation may occur at the $4^{\text {th }}$ or $5^{\text {th }}$ decade of life. The routine diagnostic investigations of intravenous or computerized tomographic scan urogram can only diagnose the PUJO with accuracy. The lucency of the crossing vessels or short segment sign [5] may suggest the presence of a crossing vessels in $20-60 \%$ of the cases [5]. The crossing vessel can be accurately detected on Helical CT angiogram or Magnetic Resonance Angiogram [MRA] [6,7]. Doppler ultrasound can also assist in making the diagnosis when angiography is not 
feasible [8]. The gold standard treatment is by Anderson- Hynes dismembered pyeloplasty which remove the abnormal PUJ and transposes the PUJ anterior to the offending vessels. This can be done laparoscopically, robotically or by open method [1, 9-11]. Alternatively, cranial relocation of the crossing polar vessel can be done by open, laparoscopic or robotic technique. This was first described by Hellstrom [12] and later modified by Chapman $[13,14]$. In the original procedure the polar vessels were anchored to the anterior pelvic wall using vascular adventitial sutures while in the modified technique the vessels were wrapped in a more superior position in the anterior pelvic wall without need of vascular adventitial sutures. No case of PUJO due to crossing lower pole vessel reported in our environment. I report a case of 45 -yearold man with congenital PUJO associated with crossing lower pole vessels who had dismembered pyeloplasty.

\section{Case Report}

This is a 45-year-old man who presented with 4 years recurrent colicky left flank pain which is relieved by passing large volume of urine. The general examination was not remarkable. The left kidney was ballotable. The abdominopelvic ultrasound and computerized urogram revealed severe left hydronephrosis and a renal stone. Full blood count, urine microscopy, urea and creatinine were normal. Clotting profile, chest $\mathrm{x}$ ray and electrocardiogram were normal. Plain abdominal $\mathrm{x}$ ray revealed radiopacity in the in the region of the right kidney (Figure 1). The diagnosis of left hydronephrosis left renal pelvic stone done. He had exploration via left Gibson incision with findings of Moderate Hydronephrosis (Figure 2), Grade II multiple crossing lower pole vessels (Figure 3) at the level of an aperistaltic PUJ which did not drain the kidney even after the transposition of the vessels posteriorly. There was no stone found. He had excision of the aperistaltic PUJ with adjoining proximal ureter and redundant pelvis. Anderson-Hynes dismembered pyeloplasty was done with the neo PUJ anterior (Figure 4) to the crossing lower pole vessels. Double J stent was inserted and a retroperitoneal drain. He was placed on the intravenous Ceftriaxone $1 \mathrm{~g}$ daily for 48 hours, pentazocine $60 \mathrm{mg}$ for 24 hours and intravenous fluid Normal saline 1L hourly for 48 hours. He was started on oral feed 2 days post operatively and the retroperitoneal drain was removed 3 days post operatively. He had uneventful recovery and was discharged home 5 days postoperatively. Stitches were removed 10 days post operatively. He was asked to come for double J stent removal 2 weeks post operatively, but he absconded with the stent in situ (Figures 1-4).

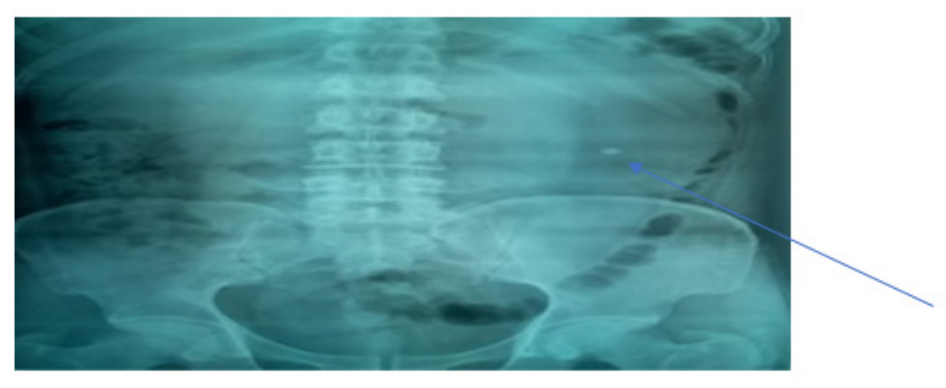

Figure 1: Plain Abdominal Showing radio-opacity in the region of left Kidney.

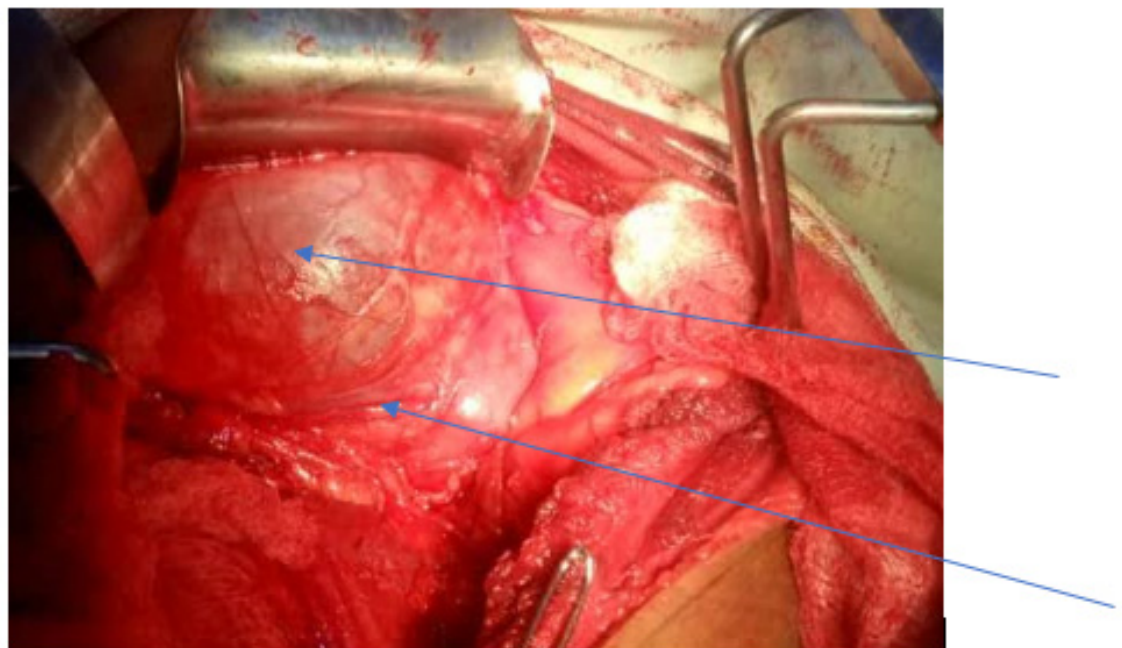

Figure 2: Intraoperative Finding of Markedly dilated left Renal Pelvis and Crossing Lower Pole Vessel at the lower part. 




Figure 3: Crossing Lower Pole Vessels at Pelvi-ureteric Junction (Shneder Class II).

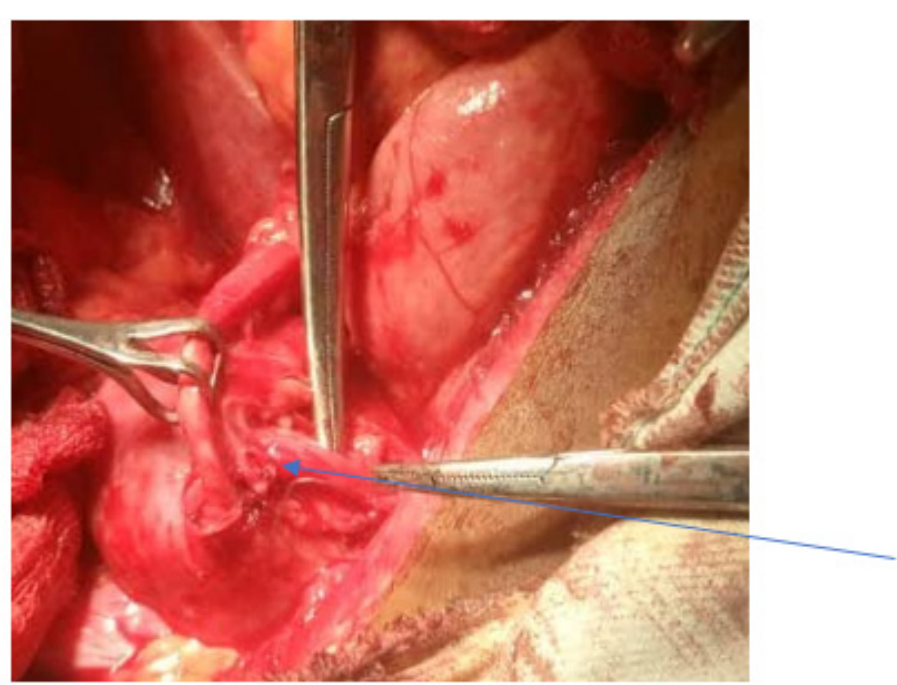

Figure 4: The Crossing Lower Pole Vessels were Transposed Posteriorly After the Pyeloplasty.

\section{Discussion}

Pelvi-ureteric junction obstruction occur due to impairment of flow of urine from the renal pelvis to the proximal ureter [2]. The obstruction can be physiologic or anatomic [2], congenital or acquired. Acquired causes are due to stones, inflammation or tumors [2]. The congenital causes can be intrinsic or extrinsic The intrinsic causes include aperistaltic segment due to abnormal musculature and valves while the extrinsic causes include adhesions, bands and crossing lower pole vessel which recently was referred to as vascular bar [2,4]. This accounted for the causes of PUJO in 11-20\% [5] and 25-50\% [15] in various studies in children and adult respectively. The obstruction can cause symptomatic progressive hydronephrosis, loss of cortical mantle, recurrent urinary tract infection, renal impairment, stone formation and hypertension warranting need for surgical intervention [2]. When there is CLPV Anderson-Hynes is indicated which will tackle all the abnormalities [2] unlike endopyelotomy which is not going to address the CLPV [2]. The diagnosis is usually incidental as doppler ultrasound of the renal vessels, computerized tomogram angiogram [CTA] or magnetic resonance angiogram [MRA] did not form routine part of PUJO investigations [5]. A low incidence of $5.6 \%$ was reported by a previous study and the authors did not recommend routine doppler or MRA to detect crossing lower pole vessel [6]. The predominant complaint of adult patients is colicky flank pain [5] which is in agreement with the present study. There was also Dietel's crisis as reported in the literature. The finding of crossing lower pole vessels is usually incidental as observed in the present study. The working diagnosis was hydronephrosis due to renal pelvic stone. The stone was not found, the possibility is the presence of dystrophic calcification in a peristaltic segment. 
Co-existing renal pelvic abnormality was found in 33\% of the cases [16]. This implies that the crossing lower pole vessels was the primary cause of the PUJO in $67 \%$ in the previous study [16]. In the present case there was co-existing PUJ abnormality which was supported by the absence of proximal ureteral dilatation and failure of urine flow after the transection of the ureter at the level of proximal ureter [5]. Anderson-Hynes dismembered pyeloplasty was done for the index as reported in the literature [2]. This allowed the transposition of the crossing vessels posteriorly and excision of the redundant renal pelvis. This can be laparoscopic, robotic or open [9-11]. Open pyeloplasty was done as we have no experience and expertise of laparoscopic pyeloplasty and no facility for robotic pyeloplasty in the area of our practice. Open pyeloplasty is still the standard of care as laparoscopic and robotic techniques though have comparable outcomes to the open technique, they are technically challenging and demanding [15]. Schneider et al [17] classified CLPV in to 3 based on intraoperative location, pelvis, PUJ and proximal ureter into class 1, 2 and 3 respectively. They advocated pyeloplasty for 1 and 2 and Hellstrom procedure for class 3 CLPV assuming the obstruction is primarily extrinsic. The index patient had class 2 CLPV which is appropriate for pyelopasty which he had. Presence of instrinsic abnormality made the index case unsuitable for Hellstrom procedure even if there is class III CLPV. The patients were mobilized early after 48 hours, drain removed in 7 hours and discharged 5 days post operatively which is comparable to the mini-invasive surgeries in terms of duration of admission and removal of drain [18].

\section{Conclusion}

Congenital Pelvi-ureteric junction obstruction associated with lower pole vessel is rare and may present in the 5 th decade of life. The main presentation is colicky pain and Dietl's crisis. The diagnosis may be incidental as doppler ultrasound and Magnetic Resonance Angiogram are not part of routine investigation for Pelvi-ureteric obstruction. Meticulous examination of vascular radiolucency and short segment sign may be done. Pelvi-uretic junction abnormality and crossing lower pole vessels may co-exist in some patients. Anderson- Hynes dismembered pyeloplasty is the procedure of choice and associated with good outcome.

\section{Acknowledgement}

I acknowledge the support of IMAN Hospital Runjin Sambo staff during management of the patients and preparation of the manuscript.

\section{Conflict of Interest}

No conflict of interest.

\section{References}

1. Panthier F, Lareyre F, Audouin M, Raffort J (2018) Pelvi-ureteric junction obstruction related to crossing vessels: vascular anatomic variations and implication for surgical approaches. Int Urol Nephrol 50(3): 385-394.
2. Nakada SY, Sara BL (2016) Management of upper urinary tract obstruction. In: Wein AJ, Partin AW, Peters CA (Eds.) Campbell -Walsh's Urology (11th edn.) Philadelphia: Elsevier Sunders p. 3357-3428.

3. Akram Assem, Hashad MM, Badawi H (2013) Retroperitoneoscopic pyelopexy for pelvi-ureteric junction obstruction with crosing vessel in adloescents: Hellstrom principle revisited. J Pediatr Urol 9: 415-418.

4. Singh SB, Vaishampayan A, Belekar D (2020) An Interesting Case of PUJ Obstruction due to a Vascular Bar. Int J Sci Res, 9(6).

5. Gupta A, Dhua A, Agarwala S, Bhatnagar V (2018) Pelviureteric junction obstruction with crossing lower polar vessel: Indicators of preoperative diagnosis. J Indian Assoc Pediatr Surg 23(3): 123-126.

6. Rigas A, Karamanolakis D, Bogdanos I, Stefanidis A, Androulakakis PA (2003) Pelvi-ureteric junction obstruction by crossing renal vessels: Clinical and imaging features. BJU International 92(1):101-103.

7. Damasio MB, Costanzo S, Podestà E, Ghiggeri G, Piaggio G, et al. (2013) Magnetic resonance urography and laparoscopy in paediatric urology: a case series. Pediatr Radiol 43(11): 1516-1527.

8. Veyrac C, Baud C, Lopez C, Couture A, Saguintaah M, et al. (2003) The value of colour Doppler ultrasonography for identification of crossing vessels in children with pelvi-ureteric junction obstruction. Pediatr Radiol 33(11): 745-751.

9. Gupta NP, Nayyar R, Hemal AK, Mukherjee S, Kumar R, et al. (2010) Outcome analysis of robotic pyeloplasty: A large single-centre experience. BJU Int 105(7): 980-983.

10. Scuderi MG, Spampinato G, Milazzo G, Betta P, Fusco M, et al. (2019) Laparoscopic transposition of lower pole crossing vessels in children with extrinsic pelvi-ureteric junction obstruction: A worthy alternative to dismembered pyeloplasty. J Biol Regul Homeost Agents 33(5 Suppl. 1): $105-110$

11. Ibrahim AG, Aliyu S, Ali N (2014) Bilateral pelvi-ureteric junction obstruction: Our experience in a developing country. Niger J Clin Pract 17: 267-269.

12. Hellstrom J, Giertz G, Lindblom K (1949) Pathogenesis and management of hydronephrosis. In: Presentedat VIII Congreso de la Sociedad Internatinale de Urologia. Paris, France.

13. Chapman TL (1959) Urology in Outline. Edinburg, London: Churchill. Livingstone p.82.

14. Esposito C, Bleve C, Escolino M, Caione P, Gerocarni Nappo S, et al. (2016) Laparoscoic transposition of lower pole crossing vessels (vascular hitch) in children with pelvi-ureteric junction obstruction. Transl Pediatr 54(4): 256-261.

15. Grasso M, Caruso RP, Phillips CK (2001) UPJ Obstruction in the Adult Population: Are Crossing Vessels Significant? Rev Urol. 3(1):42-51.

16. Janetschek G, Peschel R, Franscher F (2000) Laparoscopic pyeloplasty. Urol Clin North Am 27: 695-704.

17. Shneider A, Frerreira CG, Delay C, Lacreuse I, Moog R, et al. (2013) Lower pole vessel in children with pelvi-ureetric junction obstruction in children: laparoscopic vascular hitch or dismemebered pyeloplasty? Pediatr Urol 9: 419-423.

18. Godbole PP, Duffy PG (2007) Transposition of Lower Pole Vessels: "The Vascular Hitch". In: Godbole PP (eds) Pediatric Endourology Techniques. Springer, London. 